\title{
Transcatheter mitral valve replacement with the NaviGate stent in a preclinical model
}

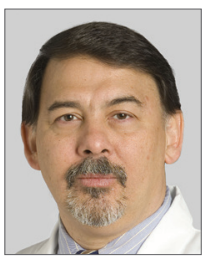

Jose L. Navia ${ }^{1 *}$, MD; Cristian Baeza ${ }^{2}$, MD; Gabriel Maluenda², MD; Samir Kapadia ${ }^{3}$, MD; Haytham Elgharably ${ }^{1}$, MD; Jerzy Sadowski ${ }^{4}$, MD; Krzysztof Bartuś ${ }^{4}$, MD; Cesare Beghi ${ }^{5}$, MD; Kalathi Thyagarajan ${ }^{6}, \mathrm{PhD}$; Ryan Bertwell ${ }^{6}, \mathrm{ME}$; Rodolfo C. Quijano ${ }^{6}, \mathrm{MD}, \mathrm{PhD}$

1. Department of Thoracic and Cardiovascular Surgery, Cleveland Clinic, Cleveland, OH, USA; 2. Hospital San Borja Arriaran, Santiago, Chile; 3. Department of Cardiovascular Medicine, Cleveland Clinic, Cleveland, OH, USA; 4. Jagiellonian University, Department of Cardiovascular Surgery and Transplantology, John Paul II Hospital, Krakow, Poland; 5. Ospedale di Circolo Polo Universitario, Varese, Italy; 6. NaviGate Cardiac Structures, Inc., Lake Forest, CA, USA

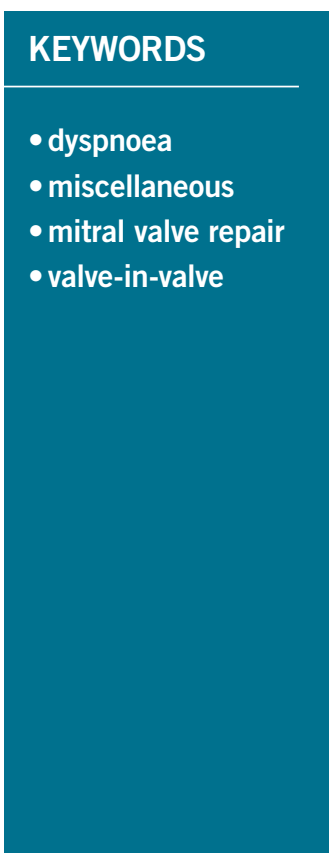

\section{Abstract}

Aims: The aim of this study was to test the feasibility of transcatheter mitral valve implantation of the NaviGate device in acute and chronic preclinical models.

Methods and results: We evaluated NaviGate valved stent implantation in the mitral position in an acute swine model ( $\mathrm{n}=24, \leq 5$ days) through three different approaches - transatrial, transapical, and transseptal - and in a chronic swine model $(\mathrm{n}=12,>10$ days) through a transatrial approach. The NaviGate implantation procedures were successful in $83 \%$ of the acute model studies $(n=20)$ and $83 \%$ of the chronic model studies $(\mathrm{n}=10)$. Echocardiographic assessment showed low gradient across the valved stent (mean gradient $<3 \mathrm{mmHg}$ ) and the left ventricular outflow tract (mean gradient $<6 \mathrm{mmHg}$ ). Post implantation, there was no mitral regurgitation (MR) in $75 \%(\mathrm{n}=15)$ of the acute studies and mild MR in $25 \%(\mathrm{n}=5)$. In the chronic model, there was no MR in $60 \%(n=6)$ and mild MR in $40 \%(n=4)$. The implantation procedure was aborted in four acute studies due to inferior vena cava injury and in two chronic studies due to prosthesis-annulus mismatch.

Conclusions: In preparation for clinical application, transcatheter mitral implantation of the NaviGate valved stent was proved feasible in acute and chronic preclinical models. The three featured delivery approaches are of particular value for high-risk patients with functional MR and challenging vascular access.

*Corresponding author: Department of Thoracic and Cardiovascular Surgery, Cleveland Clinic, 9500 Euclid Avenue/Desk J4-1, Cleveland,OH 44143,USA.E-mail: naviaj@ccf.org 


$\begin{array}{ll}\text { Abbreviations } \\ \text { LA } & \text { left atrium } \\ \text { LVOT } & \text { left ventricle outflow tract } \\ \text { MA } & \text { mitral annulus } \\ \text { MR } & \text { mitral regurgitation } \\ \text { MV } & \text { mitral valve } \\ \text { PVL } & \text { paravalvular leakage } \\ \text { TAVR } & \text { transcatheter aortic valve replacement } \\ \text { TMVR } & \text { transcatheter mitral valve replacement } \\ \text { VD } & \text { valve dislodgement }\end{array}$

\section{Introduction}

Mitral regurgitation (MR) is the most common valvular heart disease in the United States of America with a $1.7 \%$ prevalence of a moderate to severe degree in the general population ${ }^{1}$. Although there has been an increased MR prevalence in the advanced age population with comorbidities or impaired left ventricular (LV) function, surgical referral has been more frequently denied, as surgery is considered high risk ${ }^{2,3}$.

The successful implantation of a valved stent in the aortic position using a catheter-guided approach without assistance of cardiopulmonary bypass introduced new alternatives for high-risk patients ${ }^{4-6}$. Transcatheter mitral implantation has recently been a new focus of experimental research. Several devices and delivery systems of transcatheter mitral valve replacement (TMVR) are in development; however, this approach is still in its infancy ${ }^{7-10}$. Certain technical aspects render TMVR clinical application challenging, including the anatomical site, disease pathology, and complexity of the mitral valve apparatus, as well as vascular access and navigation.

The NaviGate ${ }^{\mathrm{TM}}$ valved stent (NaviGate Cardiac Structures, Inc., Lake Forest, CA, USA) was developed to address these technical aspects with a unique delivery feature that allows transcatheter implantation via three different approaches. We demonstrated the feasibility of the new valved stent in a preclinical model ahead of the intended first-in-man TMVR clinical trial.

Editorial, see page 1376

\section{Materials and methods NAVIGATE VALVED STENT}

The NaviGate device is a trileaflet valve fabricated from equine pericardium and mounted on a self-expanding tapered nitinol stent (Figure 1). Equine pericardium has the advantages of decreased thickness, superior flexibility, and increased tensile strength in comparison with other available materials such as bovine pericardium, and has been fixed with low concentrations of buffered glutaraldehyde. The NaviGate valved stent has three unique features: the cone configuration with a low height profile of $21 \mathrm{~mm}$, which produces a diffuser effect to minimise transvalvular gradients and the possibility of LV outflow tract (LVOT) obstruction; the anchoring mechanisms of the stent to the mitral annulus (MA); availability in different sizes $(36 \mathrm{~mm}, 40 \mathrm{~mm}, 44 \mathrm{~mm}, 48 \mathrm{~mm}$, and $52 \mathrm{~mm}$ ) to fit in different mitral annulus sizes. The anchoring mechanism involves 12 radially arranged winglets on the

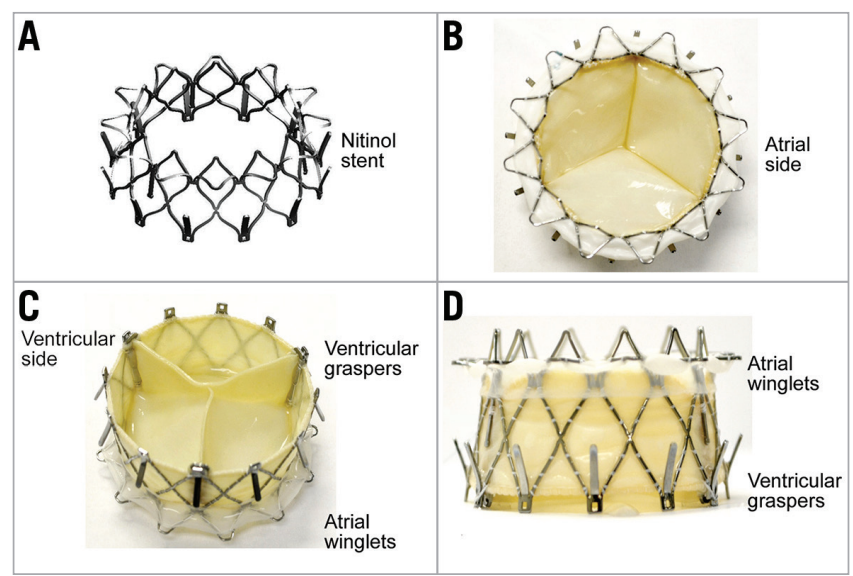

Figure 1. The NaviGate valved stent. A) Nitinol stent frame. B) Inflow (LA) view. C) Outflow (LV) view. D) Side view.

atrial component of the stent that engage the MA with a support of woven microfibre polyester fabric lining. Additionally, 12 radially arranged graspers on the ventricular component of the valved stent engage the mitral leaflets and the subvalvular apparatus within the left ventricle (Figure 2). This design secures the stent to the MA, prevents dislodgement to the left atrium during systole, minimises paravalvular leakage, and avoids coronary vessels obstruction. Compression of the circumflex coronary artery is a concern with excessive oversizing of the valved stent to the MA size. Our preference is to oversize the device by only $5-10 \%$ to the annulus size to achieve better sealing.

The NaviGate delivery system for the acute studies consists of a catheter with a central conduit accommodating a 0.038 "

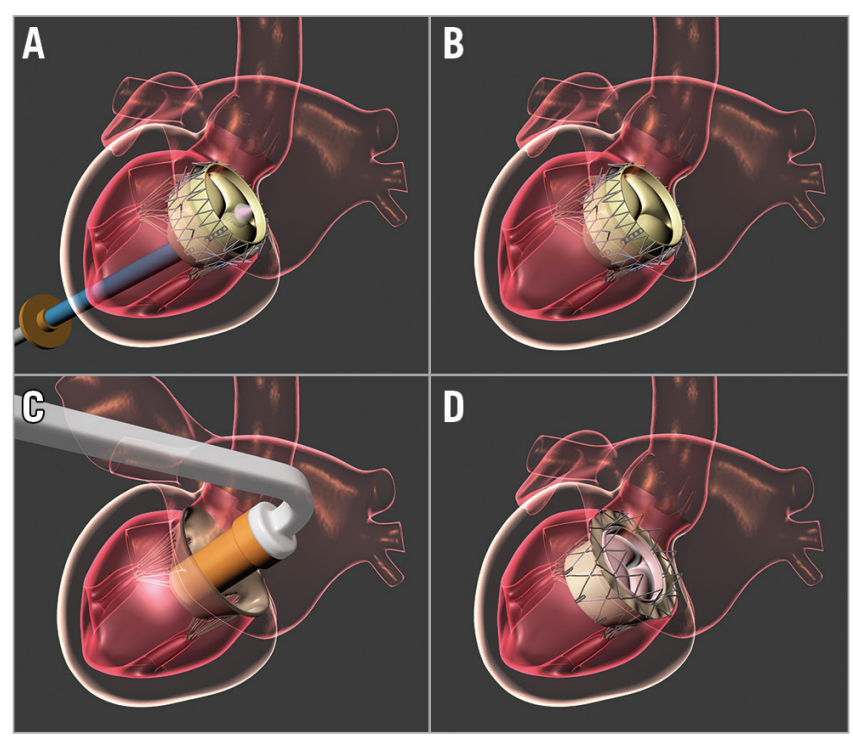

Figure 2. Mechanism of fixation: the atrial winglets engage the mitral annulus and the ventricular graspers engage the mitral leaflets and the subvalvular apparatus. A) \& B) Transapical implantation. C) \& D) Transatrial implantation. 
guidewire and has an 18 Fr shaft reinforced with interior metallic coiling. The distal section is flexible and includes the $30 \mathrm{Fr}$ stent-enclosing capsule and a mechanism that allows steering in four directions and depth control by forward or reverse motion of the distal capsule when in the immediate vicinity of the MA plane (Figure 3). The system for chronic studies evokes the configuration of a mitral commissurotomy device. The curved shape and angulation of the shaft leads the distal end into a central alignment position of the MA. The size of the distal capsule is identical to the acute delivery system (Figure 4). Retraction of the capsule causes exposure of the distal aspect of the valved stent deploying the ventricular graspers that capture the leaflets above the mitral chordae tendineae.

\section{EXPERIMENTAL DESIGN}

\section{ACUTE STUDY}

The acute study duration ranged between one and five days per protocol. The study ended with fluoroscopic imaging of the valved stent position and echocardiographic assessment of valve function. The animal was then euthanised and the valved stent examined in situ for any damage. NaviGate valved stent implantation was planned in 24 swine for acute studies, using transatrial $(n=7)$, transapical $(\mathrm{n}=9)$, and transseptal $(\mathrm{n}=8)$ approaches.

\section{CHRONIC STUDY}

The chronic study was designed to assess the durability of the valved stent after implantation in the mitral position. The initial experiments have shown that the transatrial pathway is the simplest and safest implantation approach and thus it was chosen for carrying out this study. The NaviGate valved stent implantation was planned in 12 swine that were followed to assess midterm haemodynamic function, durability, and pathological changes of the valved stent leaflets such as pannus formation, calcification, and/or thrombosis.

\section{IMPLANTATION PROCEDURE}

All animals received humane care in compliance with the Animal Welfare Act \& Public Health Services protocols. The study protocol was approved by the Institutional Animal Care \& Use Committee at the Gateway Innovation Laboratory, Shanghai, China. The size of the valved stent used in each experiment was determined by preoperative computed tomography scans as well as intracardiac echocardiograms. No rapid pacing is required for implantation of the NaviGate valved stent as the device functions during a slow controlled release when it reaches $60 \%$ of its opening diameter. During implantation, the valved stent is released from one end (atrial or ventricular) to the opposite end. For transatrial and transseptal implantation, the valved stent is released from the ventricular end to the atrial end to allow the graspers to engage the mitral leaflets and the subvalvular apparatus within the LV. For transapical implantation, it is released from the atrial end to the ventricular end to allow the winglets to engage the MA. Intracardiac and/or transoesophageal echocardiography were used for baseline evaluation before, during, and after the surgical procedures. Echocardiographic, haemodynamic, and valve function assessments were repeated after 20 minutes of haemodynamic stability. The current valved stent is no longer recapturable after the ventricular winglets come off the delivery system. A new delivery system is under development with the feature of recapturing the device after delivery.

\section{TRANSATRIAL APPROACH}

The surgical procedure involves the use of left thoracotomy through the fourth intercostal space. In the acute study, a $32 \mathrm{Fr}$ NaviGate introducer sheath $(12 \mathrm{~cm})$ was placed in the LA using the Seldinger technique (Figure $3 \mathrm{C}$ ). In chronic studies, the LA wall was opened and the new NaviGate delivery system (Figure 4) was placed, de-aired, and flushed. Using echocardiographic and fluoroscopic guidance, the valved stent-mounted delivery system was centred over the mitral valve orifice and positioned with

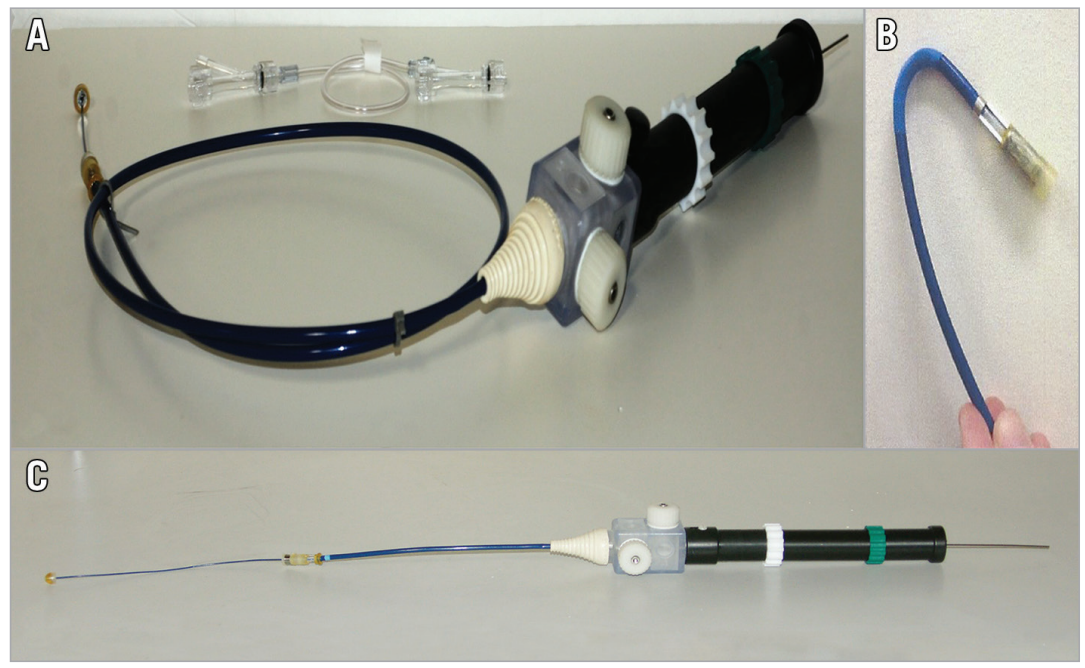

Figure 3. NaviGate valved-stent implantation delivery system. A) \& B) Acute study transseptal delivery system. C) Acute study transapical and transatrial delivery system. 


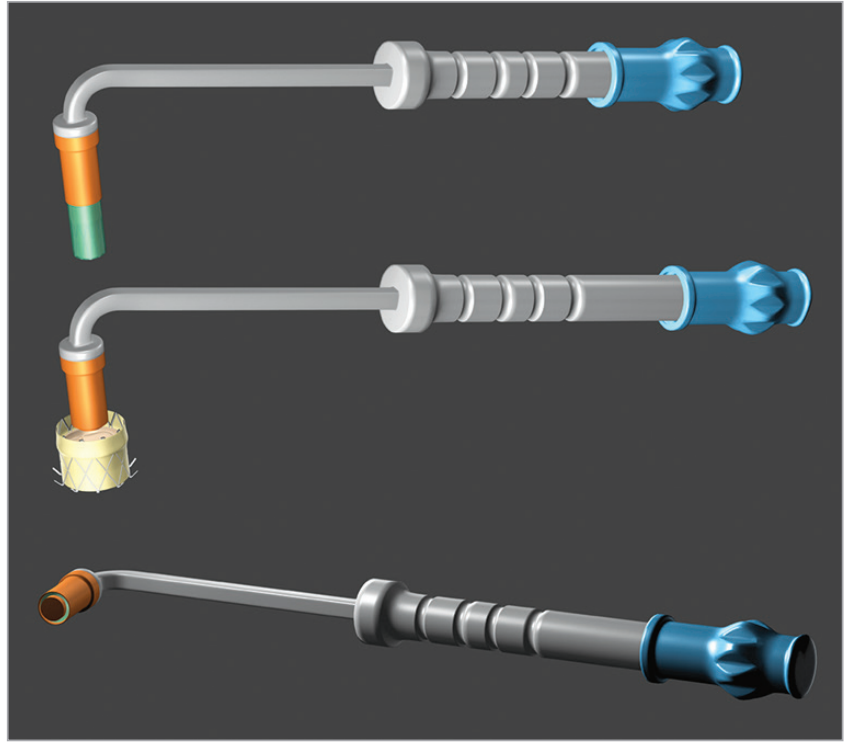

Figure 4. Chronic study transatrial delivery system.

equal valve height above and below the MA. The valved stent was deployed and anchored to the MA. Next, the delivery system was safely withdrawn, the LA puncture access site was closed using a 4-0 Prolene purse-string suture, and then the left thoracotomy was also closed in the usual fashion.

\section{TRANSAPICAL APPROACH}

The surgical procedure involves the use of the lower sternotomy or left thoracotomy through the fifth intercostal space. Using the Seldinger technique, a $32 \mathrm{Fr}$ NaviGate introducer sheath $(12 \mathrm{~cm})$ was placed for retrograde access to the MA (Figure $3 \mathbf{C}$ ). The valved stent was navigated and deployed under echocardiographic and fluoroscopic guidance. Next, the delivery system was safely withdrawn, the LV puncture access site was closed using a pursestring suture, and the incision closed in the usual fashion.

\section{TRANSSEPTAL APPROACH}

After sequential dilation of the interatrial septum access site, a 32 Fr NaviGate introducer sheath $(18 \mathrm{~cm})$ was placed for antegrade access to the MA. Then the delivery system with the NaviGate device (Figure 3A, Figure 3B) was introduced into the LA through a transseptal puncture created in the interatrial septal wall. The valved stent was navigated and deployed under echocardiographic and fluoroscopic guidance.

\section{DATA ANALYSIS}

Haemodynamic measurements after NaviGate stented valve implantation were summarised using standard descriptive statistics and are reported as mean \pm standard deviation.

\section{Results}

\section{ACUTE STUDY}

Using the three delivery modes (transseptal, transatrial, and transapical), the NaviGate valved stent was successfully implanted in 20 of the 24 animals ( $83 \%$ of the acute study). Four transseptal studies were aborted due to inferior vena cava injury. The followup varied from one to five days per protocol. Fluoroscopic and echocardiographic assessment confirmed good function of the new mitral valve with accurate alignment and secure anchoring of the valved stent onto the MA (Figure 5, Figure 6). In all cases, there was no LVOT obstruction, pericardial effusion, or encroachment on coronary arteries, along with preservation of the subvalvular apparatus. The entire procedure time in all three approaches of the acute studies ranged from 20 to $45 \mathrm{~min}$, and the device deployment time ranged from 1 to $3 \mathrm{~min}$.

\section{TRANSATRIAL DELIVERY ( $\mathrm{N}=7$ )}

There was successful implantation in all animals. Time for the device delivery at the MA after the surgical access to the left atrium was six minutes. There was no MR in five animals; one animal had central MR and one animal had mild paravalvular leak (PVL). The valve function evidenced normal haemodynamic performance and normal pressure gradient across the implanted valve (mean $2.1 \mathrm{mmHg}$ ). Mean gradient across the LVOT was $4.1 \mathrm{mmHg}$.

\section{TRANSAPICAL DELIVERY $(\mathrm{N}=9)$}

There was successful implantation in all animals. Time for the device delivery at the MA after the surgical access to the left atrium was eight minutes. There was no MR in seven animals; one animal had central MR, and one animal had mild partial valve dislodgement due to prosthesis-annulus mismatch. The dislodgement can be attributed to the undersized valved stent $(40 \mathrm{~mm})$ that was deployed in a larger mitral annular diameter ( $\geq 45 \mathrm{~mm}$ ). The valve function evidenced normal haemodynamic performance and normal pressure gradient across the implanted valve (mean $2.7 \mathrm{mmHg}$ ). Mean gradient across the LVOT was $3.7 \mathrm{mmHg}$.

\section{TRANSSEPTAL DELIVERY ( $\mathbf{N}=\mathbf{8})$}

There was successful implantation in four animals while the procedure was aborted in four animals for inferior vena cava injury. Time for the device delivery at the MA after the surgical access to the left atrium was 11 minutes. There was no MR in three animals; one animal had mild PVL. Valve function evidenced normal haemodynamic performance and normal pressure gradient across the implanted valve (mean $3.1 \mathrm{mmHg}$ ). Mean gradient across the LVOT was $3.3 \mathrm{mmHg}$ (Table 1).

\section{CHRONIC STUDY ( $\geq 10$ POSTOPERATIVE DAYS)}

The follow-up varied from 10 to 50 days per protocol. Ten of 12 animals survived the intervention; two died on the table, one from severe MR and the other one from total valve dislodgement (VD), both due to prosthesis-annulus mismatch. Of the remaining 10 animals, one animal died at 24 days due to cardiac arrhythmias, and one animal died at 54 days due to pneumonia. The other eight animals were euthanised per designated protocol - two animals after 10 days, two animals after 24 days, two animals after 30 days, and 


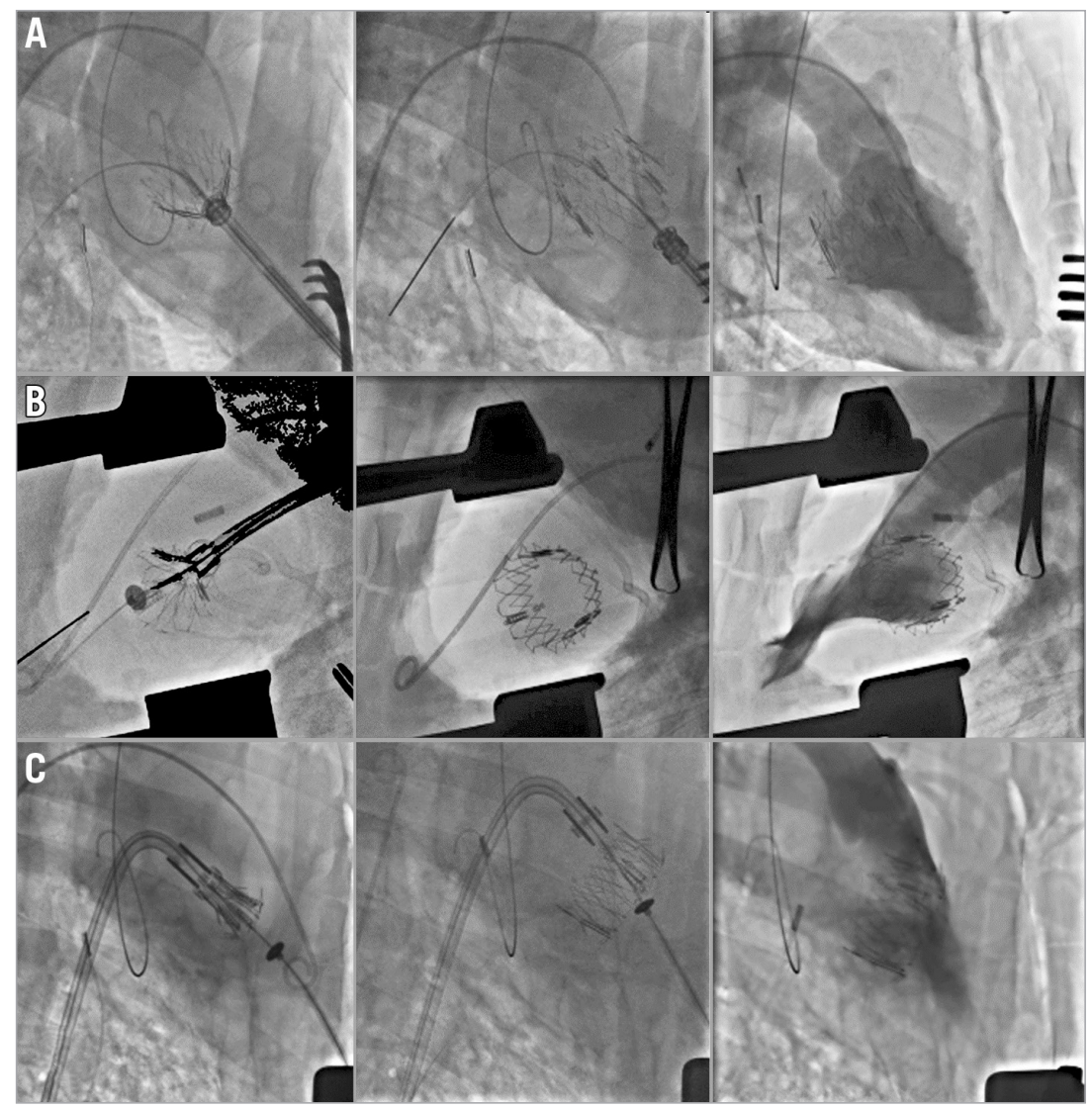

Figure 5. Acute study LV angiogram. A) Transapical. B) Transatrial. C) Transseptal.

two animals after 43 days. Fluoroscopic and echocardiographic assessment confirmed good function of the new valved stent with accurate alignment and secure anchoring of the valved stent into the MA (Figure 7A-Figure 7C).

Conformity to the MA with no PVL or central MR was observed in six valves, while one mild PVL and three mild central MR were observed. In all cases, there was no LVOT obstruction, pericardial effusion, or encroachment on the coronary arteries, along with preservation of the subvalvular apparatus.
Valve function evidenced normal haemodynamic performance and normal pressure gradient across the implanted valve, as well as LVOT gradients (Table 2).

The mean cardiac output was $3.3 \pm 1.6 \mathrm{~L} / \mathrm{min}$. There was no significant difference between the mean left atrial pressure and the LV end-diastolic pressure $(13.5 \pm 3.5$ vs. $11.2 \pm 2.6 \mathrm{mmHg})$, or across the LVOT (LV pressure $76.7 \pm 11.5$ vs. ascending aorta pressure $73 \pm 10.6 \mathrm{mmHg}$ ). The entire procedure time was in the same range as the acute-term study.

Table 1. Acute study.

\begin{tabular}{|c|c|c|c|c|c|c|c|c|c|c|}
\hline $\begin{array}{l}\text { Mode of } \\
\text { delivery }\end{array}$ & $\begin{array}{l}\text { Number of } \\
\text { animals }\end{array}$ & $\begin{array}{c}\text { Access site } \\
\text { success }\end{array}$ & $\begin{array}{l}\text { Device } \\
\text { delivery } \\
\text { success }\end{array}$ & $\begin{array}{l}\text { Time for } \\
\text { implant } \\
\text { (min) }\end{array}$ & $\begin{array}{l}\text { LVOT } \\
\text { velocity } \\
(\mathrm{m} / \mathrm{s})\end{array}$ & $\begin{array}{l}\text { LVOT } \\
\text { gradient } \\
\text { (mmHg) }\end{array}$ & 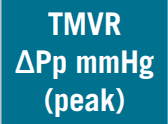 & $\begin{array}{c}\text { TMVR } \\
\Delta \text { Pm mmHg } \\
\text { (mean) }\end{array}$ & \multicolumn{2}{|c|}{$\begin{array}{c}\text { Mitral } \\
\text { regurgitation } \\
\text { Central/PVL/PVD }\end{array}$} \\
\hline Transatrial & 7 & Yes (7/7) & Yes (7/7) & 6 & 1.05 & 4.1 & 4.2 & 2.1 & $\begin{array}{l}\text { No } \\
\text { Central } \\
\text { PVL }\end{array}$ & $\begin{array}{r}5 \\
1 \\
\text { Mild } 1\end{array}$ \\
\hline Transapical & 9 & Yes (9/9) & Yes (9/9) & 8 & 1.03 & 3.7 & 5.2 & 2.7 & $\begin{array}{l}\text { No } \\
\text { Central } \\
\text { PVL } \\
\text { PVD }\end{array}$ & $\begin{array}{rr}7 \\
1 \\
0 \\
\text { Mild } 1 \\
\end{array}$ \\
\hline Transseptal & 8 & Yes (4/8) & Yes (4/8) & 11 & 0.90 & 3.3 & 6.3 & 3.1 & $\begin{array}{l}\text { No } \\
\text { Central } \\
\text { PVL }\end{array}$ & $\begin{array}{r}3 \\
0 \\
\text { Mild } 1\end{array}$ \\
\hline Total no. & 24 & 20 & 20 & 20 & 20 & 20 & 20 & 20 & & \\
\hline
\end{tabular}




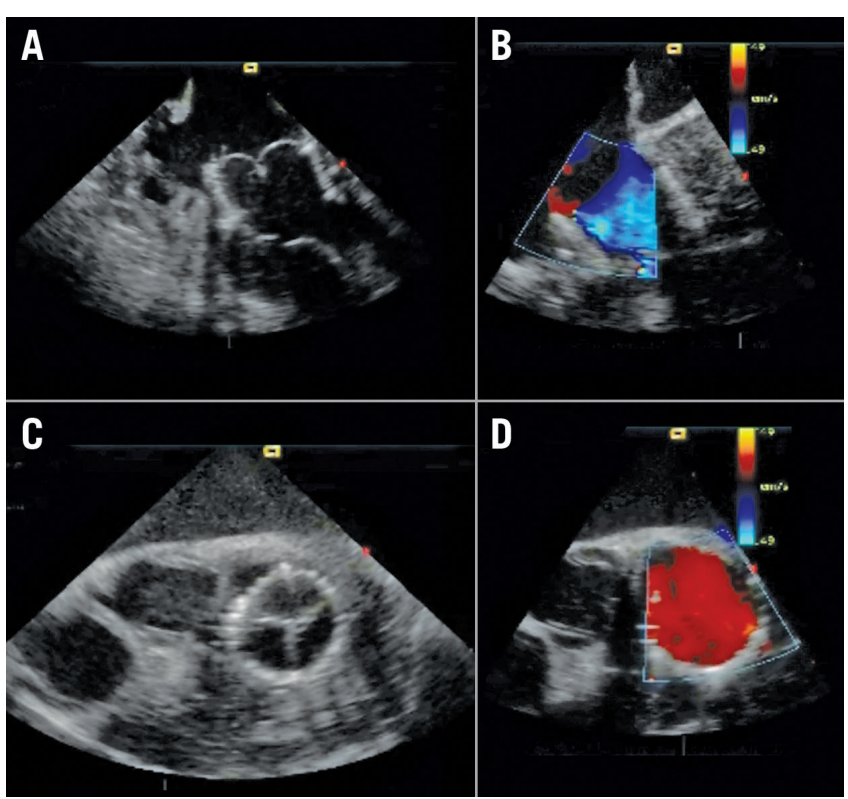

Figure 6. Acute study echocardiography. A) Long-axis view. B) Colour Doppler in long axis view. C) Short axis view. D) Colour Doppler in short-axis view.

\section{POST-MORTEM EXAMINATION}

After euthanasia, the heart was excised and weighed. A gross examination showed a proper anchoring and alignment of the valve in all the animals. There were no signs of wear or damage to the anchoring winglets. Of particular interest, the chronic tissue response to the valved stent showed normal response and evidence of tissue ingrowth without thrombus formation. There was a complete circumferential seal in both sides of the valved stent without evidence of device-related trauma (Figure 8A-Figure $\mathbf{8 C}$ ). An X-ray cell irradiator (Faxitron, Tucson, AZ, USA) was used to visualise the position of the valved stent within the MA in the resected heart which showed no distortion or fracture of any of the segments of stent in the acute or chronic study.

\section{Discussion}

The development of a clinically applicable percutaneous mitral device is more challenging compared to transcatheter aortic valve replacement (TAVR). Several technical aspects are particular to the mitral valve (MV) as the most complex heart valve and, consequently, certain considerations are required for successful TMVR ${ }^{11-14}$. The TAVR device is deployed with a sutureless implantation technique into a well-defined circular and calcified aortic valve that helps the new valved stent firmly anchor in a proper and stable position, and only needs to oppose the diastolic arterial pressures during valve closure ${ }^{15}$. The MV is a complex apparatus in which the new prosthetic valve has to anchor in a very loose and non-circular saddle-shaped annulus. In addition, it has to interact with the moving parts of the MV during the cardiac cycle, such as mitral leaflets, chordae, papillary muscles, and the LV posterior wall that induces sphincter contraction reducing

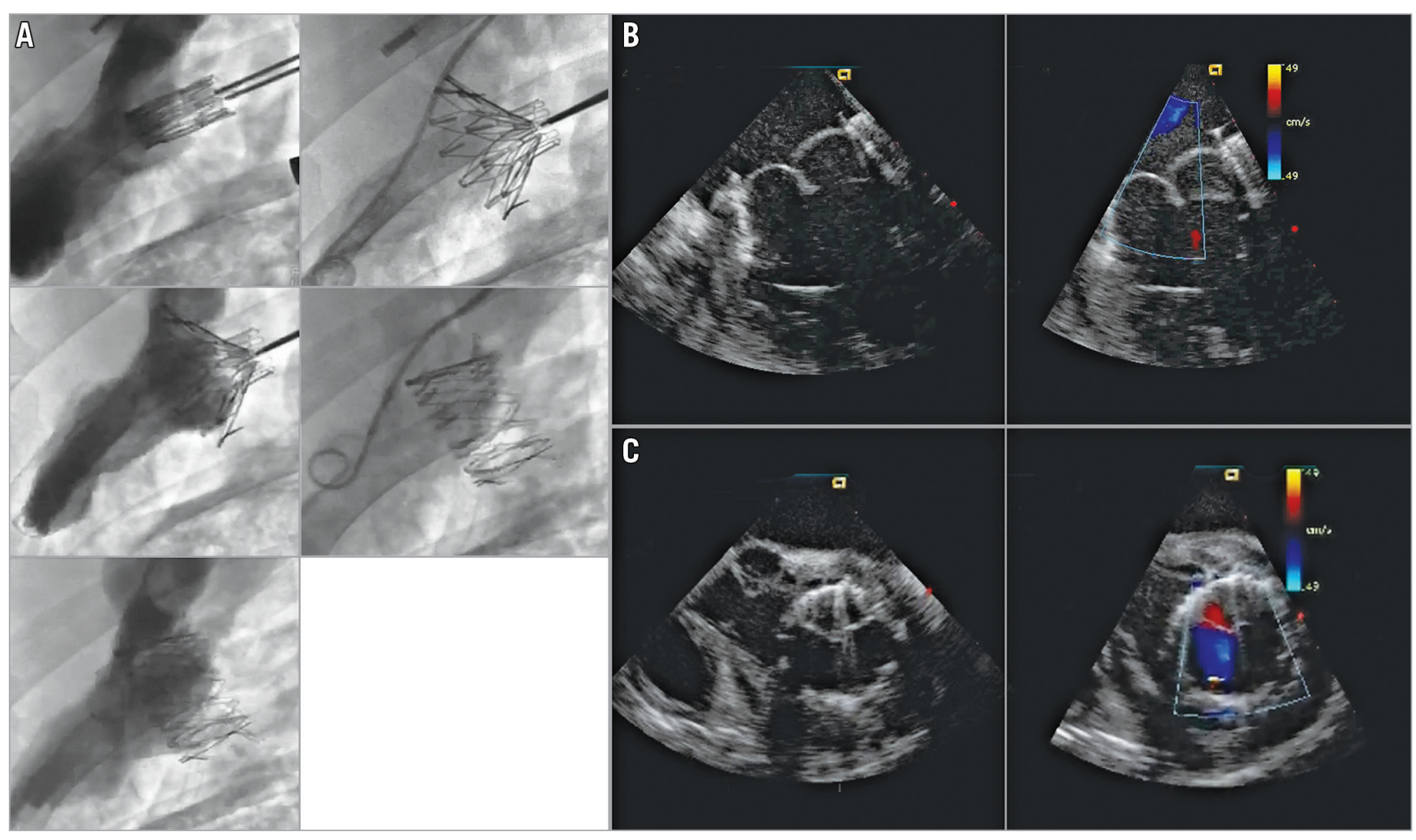

Figure 7. Transatrial NaviGate valved-stent implantation in the mitral position. A) Chronic study LV angiogram. B) Chronic study echocardiography, long-axis view. C) Chronic study echocardiography, short-axis view. 


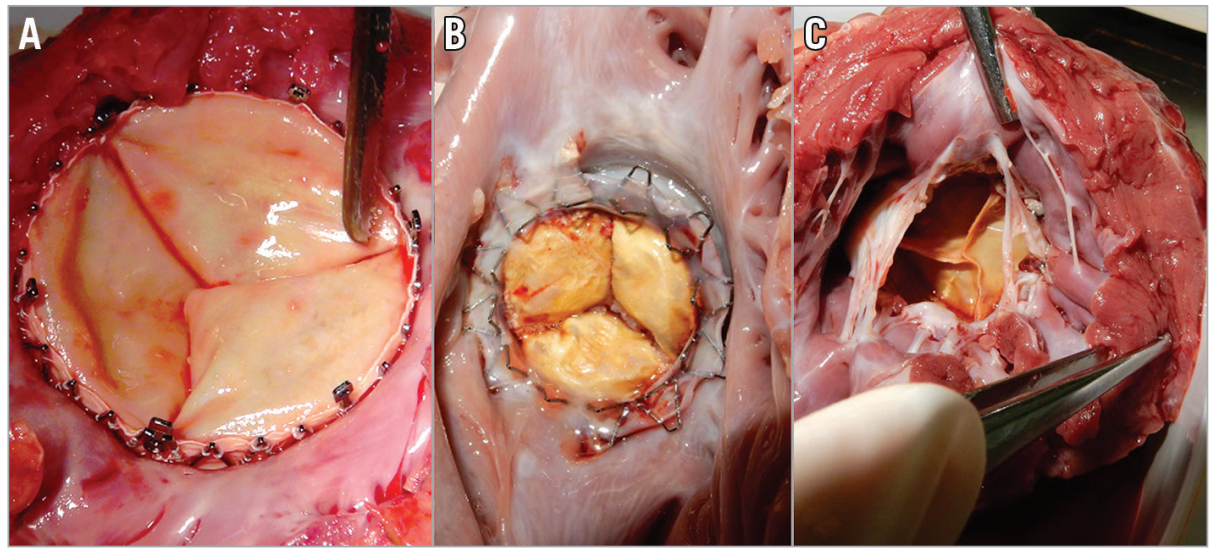

Figure 8. Post-mortem examination. A) Acute study inflow view. B) Chronic study inflow view. C) Chronic study outflow view.

the MA. All of these create a very unstable and technically challenging environment for secure valve fixation ${ }^{16,17}$.

The NaviGate valved stent was designed with particular attention to overcoming the technical challenges associated with TMVR. The feasibility of the NaviGate valved stent was tested in a preclinical model with overall satisfactory results. Echocardiography showed no significant post-implantation MR or high transvalvular gradients. There was no obstruction of the LVOT, coronary arteries, or subvalvular apparatus. Moreover, implantation of the NaviGate valved stent was successful through the three described approaches - transapical, transfemoral, and transatrial. We believe that the mitral valved stent should be larger than the native MA (oversizing may be inevitable) to achieve good anchoring of the valve within the MA. Rather than fight the MA geometry, the mitral valved stent should dictate a new MA dimension. The combination of a low profile and truncated cone self-expanding stent configuration also provides very beneficial haemodynamic parameters, low intrusion into the left atrial space, reducing (if any) PVL, and is better resistant to high dislodgement forces such as the $\mathrm{LV} \mathrm{dP/dt}$. These are the features that differentiate the NaviGate from the existing valved stents in the field. The equine pericardium is superior to other available materials such as bovine pericardium in terms of decreased thickness, superior flexibility, and increased tensile strength. Another advantage is availability in terms of quantity and cost. Durability is a concern of equine pericardium as with any other bioprosthesis; however, it was not suggested in the in vitro testing or clinical follow-up of the Medtronic $3 f$ Enable $^{\circledR}$ aortic valve (Medtronic, Minneapolis, MN, USA) ${ }^{18,19}$. An important limitation of this study is the use of healthy animal models where the MA is not enlarged with a very low atrial roof that precludes substantial extension of the valved stent into the LA. The healthy pig differs widely from the patient presenting with functional MR. The pig has a hypertrophied LV and small-chambered heart which renders navigation into the MV apparatus not a simple task. The animal ventricle pumps strongly

Table 2. Chronic study.

\begin{tabular}{|c|c|c|c|c|c|c|c|c|c|c|}
\hline $\begin{array}{c}\text { Sex, body } \\
\text { weight (kg) }\end{array}$ & $\begin{array}{c}\text { Model } \\
\#\end{array}$ & $\begin{array}{l}\text { ICE C-C } \\
\operatorname{dim}(\mathrm{cm})\end{array}$ & $\begin{array}{c}\text { Blood loss } \\
(\mathrm{ml})\end{array}$ & $\begin{array}{l}\text { Time for } \\
\text { implant } \\
\text { (min) }\end{array}$ & $\begin{array}{l}\text { TMVR } \\
\text { mmHg } \\
\text { (peak) }\end{array}$ & $\begin{array}{l}\text { TMVR } \\
\text { mmHg } \\
\text { (mean) }\end{array}$ & $\begin{array}{c}\text { LVOT } \\
\text { velocity } \\
(\mathrm{m} / \mathrm{s})\end{array}$ & $\begin{array}{c}\text { LVOT } \\
\text { gradient } \\
\text { (mmHg) }\end{array}$ & $\begin{array}{l}\text { Mitral leak } \\
\text { Central/PVL }\end{array}$ & $\begin{array}{c}\text { Duration } \\
\text { (days) }\end{array}$ \\
\hline Female, 105 & $\mathrm{X} 28$ & 4.33 & 300 & 8 & 8.2 & 3.3 & 0.95 & 3.2 & No & 10 \\
\hline Female, 101 & $\mathrm{X} 28$ & 3.76 & 350 & 9 & 8.0 & 2.4 & 1.04 & 4.3 & No & 43 \\
\hline Female, 94.5 & $\mathrm{x} 28$ & 3.86 & 250 & 3 & 6.6 & 3.2 & 1.20 & 5.9 & Mild PVL & 43 \\
\hline Female, 98 & X29 & 3.58 & 250 & 4 & 5.2 & 2.1 & 1.02 & 4.2 & No & 10 \\
\hline Male, 109 & $x 28$ & 3.96 & 1,100 & EUTH & EUTH & & & & TVD & 0.3 \\
\hline Male, 97 & X29 & 3.80 & 450 & 5 & 4.2 & 2.7 & 1.23 & 6.0 & Mild central & 24 \\
\hline Female, 104 & $\mathrm{X} 28$ & 4.13 & 230 & 5 & 6.6 & 1.7 & 2.00 & 5.8 & Mild central & 54 \\
\hline Female, 96.5 & $\mathrm{x} 29$ & 4.00 & 350 & 4 & 3.7 & 2.7 & 0.97 & 3.8 & Mild central & 24 \\
\hline Male, 96 & X29 & 3.80 & 400 & 5 & 4.1 & 2.4 & 0.97 & 3.8 & No & 30 \\
\hline Female, 83 & $x 29$ & 3.75 & 750 & EUTH & EUTH & & & & Severe MR & 0.3 \\
\hline Female, 99 & $\mathrm{x} 29$ & 3.90 & 340 & 4 & 3.1 & 1.2 & 0.92 & 3.4 & No & 24 \\
\hline Female, 92 & $x 28$ & 3.74 & 350 & 6 & 4.0 & 1.9 & 1.17 & 5.4 & No & 30 \\
\hline
\end{tabular}


generating a $\mathrm{dP} / \mathrm{dt}$ that possibly exceeds those of the normal human $(\sim 2,000 \mathrm{mmHg} / \mathrm{sec}$ at rest $)$ and definitely far exceeds the $\mathrm{dP} / \mathrm{dt}$ of the patient presenting with functional mitral regurgitation (FMR) ( 700 mmHg), so configuration of stent design is critical to absorb these forces without stent damage. The need to achieve a good measurement of the MA as well as good visualisation during deployment is critical to avoid mismatch of the valved stent to the native MA and valve migrations over time.

At this time, the NaviGate valved stent has been successfully implanted in five patients, two in the mitral position and three in the tricuspid position. Several devices have been developed for transcatheter mitral implantation and tested in animal models, and clinically ${ }^{13,14,20}$. Despite substantial technical progress in the development of valved stent designs, most of the emerging transcatheter mitral devices remain in their early development stages ${ }^{21-23}$. However, they will ultimately need to be proven safe and effective when compared to the surgical gold standard. While technically and surgically demanding, this technology may become an important alternative in a selected group of patients with high operative risk and a low probability of long-term successful MV repair ${ }^{24}$.

TMVR-associated early mortality could be attributed to application in high-risk patients with multiple comorbidities, or further impairing LV function by perforating a diseased myocardium through the transapical approach ${ }^{25}$. The next frontier for valve surgery is the development of a transcatheter-delivered mitral valved stent feasible for clinical application that requires catheter delivery into the LA via a transseptal approach or minimally invasive surgical access to the LA.

\section{Limitations}

Animportant limitation is the use of healthy animal models withnormal cardiac anatomy and physiology. Another limitation is the difficulty of applying advanced imaging technology in an animal laboratory.

\section{Conclusions}

Mitral regurgitation has a high prevalence in older patients. For those with significant comorbidities and associated high surgical risk, transcatheter mitral replacement is emerging as an alternative option to treat MR. This preclinical evaluation in acute and chronic preclinical models has shown that transcatheter implantation of the self-expanding NaviGate valved stent is feasible and safe, and results in a secure and stable engagement of the MA, with a well-functioning valve. The three delivery options suggest potential ease of implantation for high-risk patients, particularly for those with challenging vascular access.

\section{Impact on daily practice}

Transcatheter valve therapy has been progressively evolving to provide alternative options for high-risk surgical patients. In this work, we have tested the feasibility of the NaviGate valved stent in an animal model in preparation for clinical application. Three delivery approaches are of particular value for high-risk patients with functional MR and challenging vascular access anatomy.

\section{Funding}

The study was funded by NaviGate Cardiac Structures, Inc.

\section{Conflict of interest statement}

J. Navia is the inventor on patents related to this device, and is a consultant to NaviGate Cardiac Structures, Inc. (NCSI). R. Quijano is an inventor on patents related to this device, and holds stock in NCSI. K. Thyagarajan, and R. Bertwell work at NCSI. The Cleveland Clinic has an ownership position on patents licensed to and holds stock in NCSI. The other authors have no conflicts of interest to declare.

\section{References}

1. Nkomo VT, Gardin JM, Skelton TN, Gottdiener JS, Scott CG, Enriquez-Sarano M. Burden of valvular heart diseases: a population-based study. Lancet. 2006;368:1005-11.

2. Iung B, Baron G, Butchart EG, Delahaye F, GohlkeBärwolf C, Levang OW, Tornos P, Vanoverschelde JL, Vermeer F, Boersma E, Ravaud P, Vahanian A. A prospective survey of patients with valvular heart disease in Europe: The Euro Heart Survey on Valvular Heart Disease. Eur Heart J. 2003;24:1231-43.

3. Mirabel M, Iung B, Baron G, Messika-Zeitoun D, Détaint D, Vanoverschelde JL, Butchart EG, Ravaud P, Vahanian A. What are the characteristics of patients with severe, symptomatic, mitral regurgitation who are denied surgery? Eur Heart J. 2007;28: 1358-65.

4. Généreux P, Head SJ, Wood DA, Kodali SK, Williams MR, Paradis JM, Spaziano M, Kappetein AP, Webb JG, Cribier A, Leon MB. Transcatheter aortic valve implantation 10-year anniversary: review of current evidence and clinical implications. Eur Heart J. 2012;33:2388-98.

5. Elmariah S, Palacios IF, McAndrew T, Hueter I, Inglessis I, Baker JN, Kodali S, Leon MB, Svensson L, Pibarot P, Douglas PS, Fearon WF, Kirtane AJ, Maniar HS, Passeri JJ; PARTNER Investigators. Outcomes of transcatheter and surgical aortic valve replacement in high-risk patients with aortic stenosis and left ventricular dysfunction: results from the Placement of Aortic Transcatheter Valves (PARTNER) trial (cohort A). Circ Cardiovasc Interv. 2013;6:604-14.

6. Abdel-Wahab M, El-Mawardy M, Richardt G. Update on transcatheter aortic valve replacement. Trends Cardiovasc Med. 2015;25:154-61.

7. Bapat V, Buellesfeld L, Peterson MD, Hancock J, Reineke D, Buller C, Carrel T, Praz F, Rajani R, Fam N, Kim H, Redwood S, Young C, Munns C, Windecker S, Thomas M. Transcatheter mitral valve implantation (TMVI) using the Edwards FORTIS device. EuroIntervention. 2014;10 Suppl U:U120-8.

8. Banai S, Verheye S, Cheung A, Schwartz M, Marko A, Lane R, Jolicoeur EM, Garceau P, Biner S, Tanguay JF, Edelman ER, White CJ. Transapical mitral implantation of the Tiara bioprosthesis: pre-clinical results. JACC Cardiovasc Interv. 2014;7:154-62.

9. Sondergaard L, Brooks M, Ihlemann N, Jonsson A, Holme S, Tang M, Terp K, Quadri A. Transcatheter mitral valve implantation 
via transapical approach: an early experience. Eur J Cardiothorac Surg. 2015;48:873-7.

10. Lutter G, Lozonschi L, Ebner A, Gallo S, Marin y Kall C, Missov E, de Marchena E. First-in-human off-pump transcatheter mitral valve replacement. JACC Cardiovasc Interv. 2014;7:1077-8.

11. De Backer O, Piazza N, Banai S, Lutter G, Maisano F, Herrmann HC, Franzen OW, Sondergaard L. Percutaneous transcatheter mitral valve replacement: an overview of devices in preclinical and early clinical evaluation. Circ Cardiovasc Interv. 2014;7:400-9.

12. Preston-Maher GL, Torii R, Burriesci G. A Technical Review of Minimally Invasive Mitral Valve Replacements. Cardiovasc Eng Technol. 2015;6:174-84.

13. Berreklouw E, Leontyev S, Ossmann S, Velten C, Vogel B, Dhein S, Mohr FW. Sutureless mitral valve replacement with bioprostheses and Nitinol attachment rings: feasibility in acute pig experiments. J Thorac Cardiovasc Surg. 2011;142:390-5.e1.

14. Vu DT, Ti LK, Ong LC, Neo PH, Lee CN, Kofidis T. Novel sutureless mitral valve implantation method involving a bayonet insertion and release mechanism: a proof of concept study in pigs. J Thorac Cardiovasc Surg. 2012;143:985-8.

15. Cribier A, Eltchaninoff H, Bash A, Borestein N, Tron C, Bauer F, Derumeaux G, Anselme F, Laborde F, Leon MB. Percutaneous transcatheter implantation of an aortic valve prosthesis for calcific aortic stenosis: first human case description. Circulation. 2002; 106:3006-8.

16. Stone GW, Vahanian AS, Adams DH, Abraham WT, Borer JS, Bax JJ, Schofer J, Cutlip DE, Krucoff MW, Blackstone EH, Généreux P, Mack MJ, Siegel RJ, Grayburn PA, EnriquezSarano M, Lancellotti P, Filippatos G, Kappetein AP; Mitral Valve Academic Research Consortium (MVARC). Clinical Trial Design Principles and Endpoint Definitions for Transcatheter Mitral Valve Repair and Replacement: Part 1: Clinical Trial Design Principles: A Consensus Document From the Mitral Valve Academic Research Consortium. J Am Coll Cardiol. 2015;66:278-307.

17. Stone GW, Adams DH, Abraham WT, Kappetein AP, Généreux P, Vranckx P, Mehran R, Kuck KH, Leon MB, Piazza N, Head SJ, Filippatos G, Vahanian AS; Mitral Valve Academic Research Consortium (MVARC). Clinical Trial Design Principles and Endpoint Definitions for Transcatheter Mitral Valve Repair and Replacement: Part 2: Endpoint Definitions: A Consensus Document
From the Mitral Valve Academic Research Consortium. J Am Coll Cardiol. 2015;66:308-21.

18. Cox JL, Ad N, Myers K, Gharib M, Quijano RC. Tubular heart valves: a new tissue prosthesis design--preclinical evaluation of the 3F aortic bioprosthesis. J Thorac Cardiovasc Surg. 2005; 130:520-7.

19. Fuzellier JF, Campisi S, Gerbay A, Haber B, Ruggieri VG, Vola M. Two Hundred Consecutive Implantations of the Sutureless 3f Enable Aortic Valve: What We Have Learned. Ann Thorac Surg. 2016;101:1716-23.

20. Goetzenich A, Dohmen G, Hatam N, Deichmann T, Schmitz C, Mahnken AH, Autschbach R, Spillner J. A new approach to interventional atrioventricular valve therapy. $J$ Thorac Cardiovasc Surg. 2010;140:97-102.

21. Muller D, Farivar R, Jansz P, Bae R, Walters D, Clarke A, Grayburn P, Stoler RC, Dahle G, Rein KA, Shaw M, Scalia GM, Guerrero M, Pearson P, Kapadia S, Gillinov M, Pichard A, Corso P, Popma J, Chuang M, Blanke P, Leipsic J, Sorajja P; Tendyne Global Feasibility Trial Investigators. Transcatheter Mitral Valve Replacement for Patients With Symptomatic Mitral Regurgitation: A Global Feasibility Trial. J Am Coll Cardiol. 2017;69:381-91.

22. Krishnaswamy A, Mick S, Navia J, Gillinov AM, Tuzcu EM, Kapadia SR. Transcatheter mitral valve replacement: A frontier in cardiac intervention. Cleve Clin J Med. 2016;83:S10-S17.

23. Abdul-Jawad Altisent O, Dumont E, Dagenais F, Sénéchal M, Bernier M, O'Connor K, Bilodeau S, Paradis JM, CampeloParada F, Puri R, Del Trigo M, Rodés-Cabau J. Initial Experience of Transcatheter Mitral Valve Replacement With a Novel Transcatheter Mitral Valve: Procedural and 6-Month Follow-Up Results. J Am Coll Cardiol. 2015;66:1011-9.

24. Goldstein D, Moskowitz A, Gelijns A, Ailawadi G, Parides M, Perrault L, Hung S, Voisine P, Dagenais F, Gillinov A, Thourani V, Argenzino M, Gammie JS, Mack M, Demers P, Atluri P, Rose EA, O'Sullivan K, Williams DL, Bagiella E, Michler RE, Weisel RD, Miller MA, Geller NL, Taddei-Peters WC, Smith PK, Moquete E, Overbey JR, Kron IL, O'Gara PT, Acker MA; CTSN. Two-Year Outcomes of Surgical Treatment of Severe Ischemic Mitral Regurgitation. N Engl J Med. 2016;374:344-53.

25. Herrmann HC, Chitwood WR Jr. Transcatheter Mitral Valve Replacement Clears the First Hurdle. J Am Coll Cardiol. 2017; 69:392-4. 